\title{
A contribuição da ANPHLAC para o ensino e a pesquisa em História das Américas e sua inserção nas diversas regiões brasileiras ${ }^{1}$
}

Cleverson Rodrigues da Silva*

Os próximos encontros da ANPHLAC apresentarão outras faces, retratando novos passos e ângulos do processo, outras configurações com diferentes perguntas e possibilidades de avaliação ${ }^{2}$.

\section{Introdução: nascimento da ANPHLAC e histórico dos Encontros}

O momento em que a ANPHLAC (Associação Nacional de Pesquisadores e Professores de História das Américas) completa 20 anos serve como oportunidade para refletirmos sobre os caminhos percorridos pela entidade nestas duas décadas de existência e sobre sua contribuição ao desenvolvimento do ensino e da pesquisa da História das Américas no Brasil.

Ao longo destes 20 anos, a Associação contribuiu significativamente para o desenvolvimento da área de História das Américas no Brasil e também para a aproximação entre professores, pesquisadores e estudantes envolvidos com a temática no Brasil e no continente americano. Inicialmente, concentrou sua atenção nos estudos latino-americanos e caribenhos, e, na última década, estendeu seu foco para todo o continente, incluindo os Estados Unidos da América e o Canadá.

A preocupação com o fortalecimento do ensino e da pesquisa da área de História das Américas no Brasil encontra-se na origem da formação da entidade, como se pode constatar na forma como ela se apresenta:

A Associação Nacional de Pesquisadores e Professores de História das Américas-ANPHLAC se dedica ao estudo, à pesquisa e à divulgação de assuntos referentes à História da América Latina e Caribe. Seu surgimento

\footnotetext{
${ }^{1}$ Este artigo foi escrito com a colaboração da professora Heloísa Jochims Reichel, que generosamente opinou com algumas correções e informações.

* Doutor em História Latino-Americana - UNISINOS. Professor da Universidade Federal de Mato Grosso do Sul - Campo Grande/MS. E-mail: cleverson.silva@ufms.br

2 Jaime de Almeida. Caminhos da História da América no Brasil, ANPHLAC, 1998, pág. 19.
} 
aconteceu durante a década de 90, a partir da iniciativa de alguns profissionais da área que, preocupados com a marginalidade dos estudos latino-americanos na década de 80, tiveram a certeza de que se fazia necessário tomar medidas concretas e urgentes. Neste sentido, um grupo de pesquisadores se encontrou em janeiro de 1992 em São Paulo, decidindo organizar, como primeiro passo, um Comitê que foi chamado de - Comitê Nacional de Pesquisadores e Professores de História da América Latina e Caribe (CONAPHLAC). (Abertura do site da ANPHLAC www.anphlac.org)

Segundo o professor Jaime de Almeida (1998, p. 14), a CONAPHLAC tinha os seguintes objetivos:

a) Estimular a formação de pesquisadores em História da América Latina no Brasil;

b) Divulgar as pesquisas entre profissionais da área;

c) Proporcionar contatos entre profissionais da área;

d) Estimular a discussão sobre a avaliação do ensino e de pesquisa em História da América Latina nas Universidades brasileiras;

e) Sistematizar encontros de estudiosos de América Latina, através da realização de Seminários temáticos e da formação de grupos de trabalho;

f) Promover Encontros bianuais de pesquisadores professores da área a nível nacional".

Coordenada pela professora Heloísa Jochims Reichel, a reunião aconteceu em 25 de fevereiro de 1992. Sobre os motivos que levaram à fundação da ANPHLAC, a professora referiu:

\begin{abstract}
Uma das razões que motivou os professores de História da América de algumas universidades brasileiras a se reunir, em fevereiro de 1992, para dar o pontapé inicial à ANPHLAC foi a escassa oferta de obras publicadas no Brasil, relativas ao conteúdo da disciplina. A esta dificuldade, associava-se o reduzido, quando não ainda desatualizado, acervo das bibliotecas universitárias. Era comum, assim, que, nos cursos de graduação em História, principalmente no de universidades mais distantes dos principais centros culturais do país ou nos de recente criação, a temática latino-americana fosse ensinada através de uma bibliografia defasada, escassa e limitada. A pesquisa, por sua vez, também era restrita não apenas pela falta de acesso à documentação, mas pela própria dificuldade de se poder avaliar o estado geral da arte e, dessa maneira, problematizar temáticas relativas à história da América. (Reichel, Revista Eletrônica ANPHLAC, 2001, p. 7)
\end{abstract}

Considerando, pois, os objetivos de estímulo à pesquisa em História das Américas no Brasil que motivaram a formação da ANPHLAC e o papel agregador de 
docentes e discentes que ela tem conseguido desempenhar ao longo de sua existência, pensamos que é possível traçar um mapa da produção historiográfica sobre História das Américas no Brasil, sem com isso esgotar todas as possibilidades, tendo como foco os Encontros realizados pela Associação e as publicações da Revista Eletrônica da ANPHLAC. A esta tarefa nos debruçaremos a seguir.

Antes, porém, cabe reforçar que o período de gestação da ANPHLAC, que corresponde à segunda metade dos anos 80 e princípios dos 90, foi marcado pelo início de "uma produção historiográfica consistente acerca das Américas, principalmente sobre a América Hispânica”. Houve, neste momento, segundo a professora Heloísa Jochims Reichel, um crescimento "quantitativo e qualitativo" da mesma que coincidiu com a ampliação dos Programas de Pós-Graduação em História nas universidades brasileiras, notadamente de alguns que concentravam seus estudos em temas da história latino-americana, como os da UFRGS, UNISINOS e PUC/RS, este já existente desde 1973.

O evento em que se deu a criação da ANPHLAC aconteceu entre os dias 12 e 15 de janeiro de 1993, na Universidade Federal de Ouro Preto, campus de Mariana. O encontro, que contou com a participação de professores e pesquisadores de vários estados do Brasil, culminou com a aprovação do documento de Mariana $^{3}$ e a eleição da primeira diretoria da Associação Nacional de Pesquisadores de História Latinoamericana e Caribenha - ANPHLAC -, cuja presidência ficou para a professora Philomena Gebran.

O estatuto da nova Associação foi aprovado em junho de 1993 durante o XVII Simpósio Nacional da ANPUH. Também, na ocasião, ficou decidido que o I Encontro aconteceria em 1994, no Rio de Janeiro, “integrando-se a série de eventos que, em vários países, comemorariam o Centenário do intelectual peruano José Carlos Mariátegui”. (Almeida, 1998, p. 15, 1998)

\footnotetext{
${ }^{3} \mathrm{O}$ documento de Mariana que deu origem a ANPHLAC, segundo a professora Philomena Gebran, foi assinado pelos professores e pesquisadores Alberto Aggio (UNESP), Ana Maria Martinez (UNESP ASSIS) Cecília Azevedo (UFF), Izabel (Gama Filho), Fátima Gouvea (UFF) Hector Bruit (UNICAMP), Heloisa Jochims Reichel (UFRGS), Lilia Medrano (PUCCAMP), Kátia Gerab (UFOP), Lina Aras (UFBA), Maria Helena R. Capelato (USP), Maria Lígia Coelho Prado (USP), Maria Teresa Toríbio B. Lemos (UERJ), Philomena Gebran (UFRJ) e Ronaldo Vainfas (UFF). Fonte: Revista Eletrônica ANPHLAC, No. 1, pp. 5 e 6.
} 
O I Encontro da ANPHLAC Políticas e Cultura na América Latina: os cem anos de Nascimento de José Mariátegui, com recursos concedidos pelo CNPq e apoio do Programa de Estudos de América Latina e Caribe (PROEALC) da UERJ, realizou-se no Rio de Janeiro entre os dias 28 de novembro e 02 de dezembro de 1994, na UERJ, com a participação de pesquisadores brasileiros e hispano-americanos. Algumas publicações ali apresentadas foram depois publicadas no Peru pela Empresa Editorial Amauta. (Almeida, 1998, p. 15, 1998)

A importância deste Encontro reside no fato de ser a concretização de um processo que vinha sendo gestado desde a década de 1980 e o primeiro grande passo para a consolidação da subárea de História da América Latina. Importante também, porque coincide com o momento imediatamente posterior a uma pesquisa da CAPES realizada em meados dos anos de 1980 -, apontando a péssima "situação que se encontravam os Cursos de História e a pesquisa sobre América Latina no Brasil”. (Gebran, Revista Eletrônica da ANPHLAC, No. 1, 2001, p. 3 com modificações)

Dizia a CAPES: “a área de História da América Latina nas Universidades está tão defasada que, se não forem tomadas providências urgentes, em muito pouco tempo não haverá mais professores de História da América Latina nas Universidades brasileiras". (Gebran, Revista Eletrônica da ANPHLAC, No. 1, 2001, p. 3)

Em 1996, aconteceria o II Encontro, considerado como "uma etapa importante na progressão desse processo de organização". Era o momento oportuno para "avaliar as características, problemas e perspectivas recentes da produção acadêmica brasileira da subárea, especialmente a partir do Encontro de Mariana promovido pela CONAPHLAC, do qual resultara a criação da associação". (Almeida, 1998, p. 15, com modificações).

Segundo o professor Jaime de Almeida, o objetivo principal do Encontro era fortalecer internamente a associação. "Tratava-se de cumprir uma das prioridades a curto prazo fixadas pelo Documento de Mariana: investir na formação de quadros e na constituição de acervos bibliográficos e documentais na área de História do Caribe e da América Latina de colonização espanhola", e para isto, deveriam ser realizados eventos que possibilitassem a "avaliação de Estudos Latino-Americanos em andamento no país e no continente". (Almeida, 1998, p. 16) 
Ainda, segundo o professor, "Brasília foi escolhida como sede do II Encontro para enfatizar a prioridade na tarefa de organização da subárea, pois aí se encontram as sedes das agências federais de fomento - CNPq e CAPES”. (Almeida, 1998, p. 15)

Os desdobramentos do Encontro foram muito positivos, uma vez que despertou a atenção de alguns historiadores estrangeiros, permitindo que estes tivessem uma ideia do estado da arte no Brasil, em contrapartida, "os pesquisadores estrangeiros muito contribuíram na troca de experiências". (Almeida, 1998, p. 15, com modificações)

Após quatro encontros (1994, 1996, 1998 e 2000), o quinto, realizado na cidade de Belo Horizonte em 2002, marcou uma mudança importante na trajetória da Associação, houve uma alteração no Estatuto, "com o objetivo de contemplar as novas pesquisas que surgiam no âmbito da História das Américas no Brasil, incluindo em particular os pesquisadores que se dedicam à História dos Estados Unidos e do Canadá, além das interconexões entre estes e os países da América Latina”. No ano de 2007, visando uma adequação ao novo Código Civil, "ocorreu uma grande reformulação estatutária", passando a Associação a se chamar Associação Nacional de Pesquisadores e Professores de História das Américas, mantendo a sigla anterior, ANPHLAC. (Histórico ANPHLAC - www.anphlac.org, com modificações)

\begin{abstract}
Desde então, os congressos da Associação têm acontecido a cada dois anos, em diversas cidades e regiões do país. A ANPHLAC, atualmente, tem como objetivo principal congregar os pesquisadores que se dedicam à pesquisa e à docência em História das Américas, nas mais diversas dimensões desse conhecimento. Além disso, pretende contribuir para o aperfeiçoamento do ensino de História das Américas em seus diversos níveis e estimular o estudo, a pesquisa e a divulgação de assuntos referentes à História das Américas. Empenha-se, também, em defender a conservação das fontes e manifestações culturais de interesse dos estudos históricos americanos, além de promover a permuta de ideias e informações entre seus associados, por meio de encontros e reuniões periódicas e de publicações impressas e eletrônicas, assim como estimular o intercâmbio entre especialistas nacionais e estrangeiros. (Histórico ANPHLAC - www.anphlac.org)
\end{abstract}

Desse modo, o objetivo deste artigo é traçar um panorama dos 20 anos da Associação através de sua produção bibliográfica e sua trajetória como entidade que tem buscado a aproximação entre professores, pesquisadores e estudantes envolvidos com a temática no Brasil e no continente americano.

Para realização deste artigo as fontes consultadas foram o site da ANPHLAC (www.anphlac.org) em seus Anais, abertura, histórico, a Revista Eletrônica da 
ANPHLAC e os dois livros citados anteriormente. A metodologia adotada foi uma análise da produção contida nestas fontes, com levantamento de dados sobre o número de produções, autores, origem dos pesquisadores e das pesquisas e as temáticas abordadas ao longo das duas décadas de existência da Associação, sem, contudo, conforme já mencionado, esgotar as possibilidades.

\title{
O mapa da produção historiográfica sobre a História das Américas no Brasil segundo a produção chancelada pela ANPHLAC
}

O primeiro trabalho surgido do Encontro realizado no Rio de Janeiro e que deu origem às publicações da ANPHLAC (livros, anais dos Encontros e na Revista Eletrônica da Associação), foi o livro Cultura, Estado e Sociedade: novas perspectivas, organizado pelas professoras Philomena Gebran e Maria Teresa Toríbio B. Lemos. Este livro é o marco zero das publicações oficiais da ANPHLAC que culminaria depois de 20 anos com os anais de dez Encontros ${ }^{4}$ e 13 números da Revista Eletrônica da Associação.

A importância deste livro reside no fato não somente de ser a primeira publicação da Associação e o resultado do I Encontro, mas, sobretudo, porque marca o início das publicações da ANPHLAC e a quebra de uma tradição. "Durante décadas recebemos conceitos europeus prontos e análises eurocêntricas distorcidas da realidade e das raízes culturais aqui existentes”. (Gebran, 1994, p. iv)

Ainda Segundo Philomena Gebran,

\begin{abstract}
Apesar da riqueza de suas culturas, a América Latina foi sempre uma região meio esquecida pelos estudiosos brasileiros de História, que dirigiram seus estudos e pesquisas visando a realização de uma História nacional, brasileira, ou, em outras áreas, com um olhar voltado mais para o Atlântico que para a realidade latino-americana. Essa questão agravou-se com os anos das ditaduras, vividas pela maioria dos países, que terminaram por isolar-se cada vez mais, tornando a sonhada integração uma utopia. (Gebran, 1994, p. iii)
\end{abstract}

Já, o II Encontro realizado em Brasília em 1996 deu origem ao livro do professor Jaime de Almeida Caminhos da História da América no Brasil: tendências e contornos de um campo historiográfico. Segundo o professor,

\footnotetext{
${ }^{4}$ Os Anais do último Encontro, o X Encontro Internacional da ANPHLAC não serão analisados neste artigo, uma vez que, o mesmo ainda não estava disponível no site da Associação quando este artigo foi escrito.
} 
Este livro reúne praticamente todas as comunicações apresentadas no II Encontro da ANPHLAC, mas não adota o formato de anais. A Assembleia Geral da associação, realizada no interior no XIX Simpósio Nacional da ANPUH em julho de 1997, em Belo Horizonte, optou pela edição do um livro que responda a uma carência do mercado editorial. Efetivamente, os professores e estudantes de História da América no Brasil têm à sua disposição obras reconhecidas de padrão acadêmico; no entanto, há um vácuo entre as grandes coleções, em geral pouco acessíveis, e uma variedade de estudos monográficos dispersos. (Almeida, 1998, p. 18)

As publicações presentes no livro podem ser visualizadas no quadro abaixo, que representa os temas que foram abordados e as instituições de origem dos professores e pesquisadores que publicaram suas comunicações no livro.

Quadro 1: Temas e Instituições participantes do livro Caminhos de História da América no Brasil

\begin{tabular}{|c|c|c|c|c|c|c|c|c|c|c|c|c|c|}
\hline $\begin{array}{c}\text { Tema } \\
\text { Instituição }\end{array}$ & $\mathbf{1}$ & $\mathbf{2}$ & $\mathbf{3}$ & $\mathbf{4}$ & $\mathbf{5}$ & $\mathbf{6}$ & $\mathbf{7}$ & $\mathbf{8}$ & $\mathbf{9}$ & $\mathbf{1 0}$ & $\mathbf{1 1}$ & $\mathbf{1 2}$ & Total \\
\hline UNESP & 1 & 1 & & & & & & & & & 2 & & $\mathbf{4}$ \\
\hline UFRJ & 1 & & 1 & & & & & & & & & & $\mathbf{2}$ \\
\hline UNISINOS & 1 & & 3 & & & & & & & & & & $\mathbf{4}$ \\
\hline UnB & 1 & & 2 & & 4 & 3 & 3 & 5 & & 2 & & 1 & $\mathbf{2 1}$ \\
\hline UFG & & 1 & & 3 & 1 & & 1 & & & 2 & & & $\mathbf{8}$ \\
\hline UFMG & & 1 & & & & & & & & & & & $\mathbf{1}$ \\
\hline PUCCAMP & & & 1 & & & & & & & & & & $\mathbf{1}$ \\
\hline USP & & & 1 & & & & & & & 1 & & & $\mathbf{2}$ \\
\hline UFF & & & & & 1 & & & & & & & & $\mathbf{1}$ \\
\hline GLASGOW & & & & & 1 & & & & & & & & $\mathbf{1}$ \\
\hline PARIS IV & & & & & & & & 1 & & & & & $\mathbf{1}$ \\
\hline UNIV. & & & & & & & & & 1 & & & & $\mathbf{1}$ \\
\hline VERACRUZANA & & & & & & & & & & \\
\hline
\end{tabular}

\footnotetext{
5 Temas: 1) Historiografia; 2) História das Ideias; 3) Região Platina; 4) Literatura e História; 5) Gênero e Grupos Etários; 6) Popayán, Colômbia; 7) Rostos Índios da América; 8) A América nas Relações Internacionais; 9) Veracruz, México; 10) Trabalho, Migração, Cultura e Identidade; 11) História Política: o Chile; e 12) Perspectivas do Ensino de História da América.
} 


\begin{tabular}{|c|c|c|c|c|c|c|c|c|c|c|c|c|c|}
\hline UNAM & & & & & & & & & 1 & & & & $\mathbf{1}$ \\
\hline UFC & & & & & & & & & & 1 & & & $\mathbf{1}$ \\
\hline UFBA & & & & & & & & & & & & 1 & $\mathbf{1}$ \\
\hline UFSC & & & & & & & & & & & & 1 & $\mathbf{1}$ \\
\hline TOTAL & $\mathbf{4}$ & $\mathbf{3}$ & $\mathbf{8}$ & $\mathbf{3}$ & $\mathbf{7}$ & $\mathbf{3}$ & $\mathbf{4}$ & $\mathbf{6}$ & $\mathbf{2}$ & $\mathbf{6}$ & $\mathbf{2}$ & $\mathbf{3}$ & $\mathbf{5 1}$ \\
\hline
\end{tabular}

Fonte: Caminhos da História da América no Brasil: tendências e contornos de um campo historiográfico.

Convém ressaltar que, este Encontro, segundo o professor Jaime de Almeida foi extremamente importante, não somente por ser o segundo, mas pelo fato de ser ainda um momento de consolidação da Associação.

Podemos notar, conforme o quadro acima que a grande maioria dos participantes eram procedentes de Brasília e Goiânia, locais próximos ao Evento. Também é possível notar a participação significativa de duas instituições distantes do local do Encontro, UNISINOS e UNESP.

Os temas mais abordados neste Encontro foram Região Platina, Gênero e Grupos Etários seguidos de Relações Internacionais e Trabalho, Migração, Cultura e Identidade.

O quadro revela ainda que, já neste Encontro houve uma participação significativa de pesquisadores de universidades estrangeiras, somando-se um total de 4 participantes de 4 Universidades diferentes.

O Evento se abriu com a Conferência "A resistência indígena de Chiapas, da colônia ao atual movimento zapatista" apresentada pelo doutor Antonio García de León, da UNAM. O programa se desdobrou em sessões de trabalho por eixos temáticos, um fórum dedicado aos problemas do ensino de História da América no Brasil, assembleia geral, atividades culturais e de congraçamento (...). (Almeida, 1998, p. 16)

A partir do III Encontro, realizado em São Paulo, entre os dias 22 e 24 de julho de 1998, as publicações começaram a sair em forma de Anais. Neste Encontro "os inscritos - contando participantes com trabalhos e simples assistentes - somaram 176. Entretanto, a assistência às diversas atividades do Encontro superou de muito esta marca, pois as salas onde aconteceram as apresentações contaram sempre com público 
numeroso". (Anais do III Encontro ANPHLAC. Apresentação, Maria Ligia Coelho Prado, 1998, p. 1)

O formato e o tamanho do Encontro indicaram outras facetas positivas. Houve a possibilidade de um acompanhamento efetivo de temáticas ou abordagens da preferência de cada participante, pois a montagem das mesas favorecia tais escolhas. O interessado podia seguir, por exemplo, uma sequencia de mesas sobre História Política, História das Idéias, ou História Social. Assim, a assistência, além de numerosa contribuiu para que os debates fossem mais estimulantes e frutíferos. (Anais do III Encontro ANPHLAC. Apresentação, Maria Ligia Coelho Prado, 1998, p. 2)

Podemos evidenciar isto no quadro abaixo, através da diversidade dos temas abordados, bem como a origem dos pesquisadores que participaram do Encontro. 
Quadro 2: Temas e origem dos pesquisadores com publicações nos Anais do III Encontro Internacional ANPHLAC

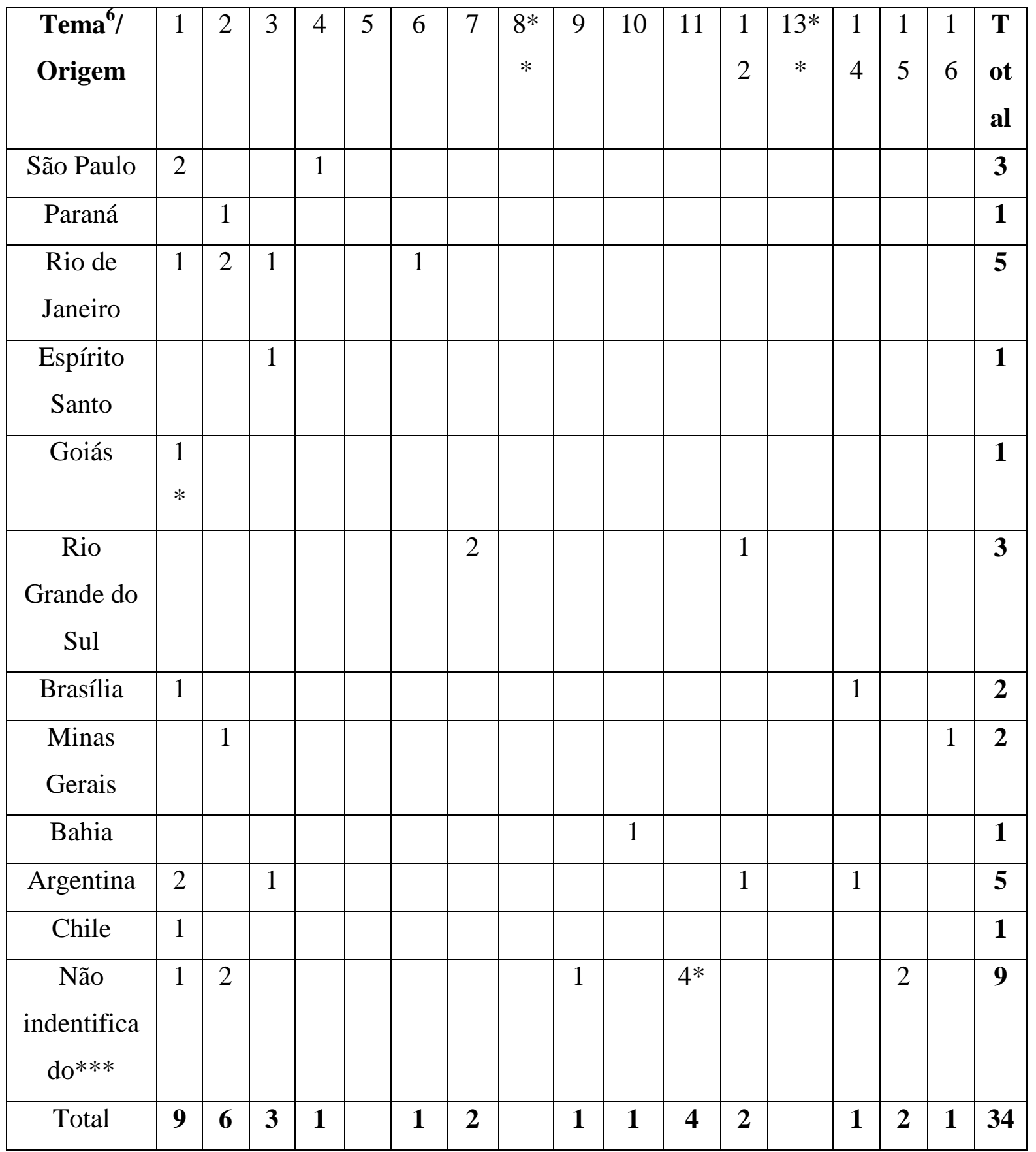

Fonte: Anais do III Encontro da ANPHLAC. www.anphlac.org.

${ }^{6}$ Temas: 1) América Latina; 2) Biografia; 3) Argentina; 4) Uruguai; 5) Venezuela; 6) Peru; 7) Missões Jesuíticas; 8) Cuba-Argentina; 9) Equador; 10) Brasil-América Latina; 11) Cuba; 12) Argentina-Uruguai; 13) América; 14) Brasil-Argentina; 15) Bolívia; e 16) Porto Rico.

* Artigo com dois ou mais autores.

** Estudo comparativo entre países e América Latina. Já mencionado no tema 1, América Latina.

*** Artigos onde não foram possíveis identificar a origem do autor (es). 
Os artigos que constam nos anais do evento apontam que a produção originou-se basicamente das regiões sul e sudeste, tendo os seguintes números:

Da programação constava a apresentação de duas conferências magnas e de trinta e duas mesas redondas. Estas, sempre coordenadas por um professor convidado, se organizaram de forma padronizada, com três expositores, cada um com 20 minutos de tempo para fazer sua exposição. Em seguida aconteciam os debates, com a participação do coordenador e do público. A presença de alunos de graduação na platéia se mostrou como um sinal positivo do interesse que as temáticas escolhidas suscitaram. Como a área de História da América é, em todo o Brasil, carente de especialistas, foi alentador constatar a presença desses jovens, futuros pesquisadores em potencial. (Anais III Encontro, apresentação, professora Maria Ligia, 1998, p. 2)

Desse modo, a produção teve como principais pesquisadores cinco do Rio de Janeiro, cinco da Argentina, três de São Paulo e três do Rio Grande do Sul. As pesquisas trouxeram como temática principal a América Latina ${ }^{7}$, Argentina e comparação Brasil-Argentina.

O IV Encontro realizado em Salvador na Universidade Federal da Bahia (UFBA) entre os dias 09 e 11 de novembro de 2000, "agregou pesquisadores de instituições nacionais e Latino-americanas”.

Segundo a professora Lina Maria Brandão de Aras,

A variedade de temáticas ali expostas apontam para a ampliação das pesquisas e do número de pesquisadores, ao tempo em que conquista outros espaços na área da História da América. Tal movimento é fruto de um esforço de pesquisadores, que desde o final dos anos oitenta do século findo, dedicam sua produção acadêmica em direção a implementação dos estudos nessa área do conhecimento. (Anais do IV Encontro ANPHLAC. Apresentação, Lina M. B. Aras, 2000, p.1)

Merece destaque a ampliação das fronteiras cronológicas, podendo encontrar trabalhos para períodos distintos, especialmente o período colonial, sem abandonar as grandes temáticas já consagradas na historiografia latinoamericana. A riqueza das informações evidencia o trabalho persistente do historiador na busca de tornar conhecidas as formações históricas nas América. (Anais do IV Encontro ANPHLAC. Apresentação, Lina M. B. Aras, 2000, p.1)

\footnotetext{
${ }^{7}$ Aos nos referirmos que as pesquisas apresentadas foram sobre a América Latina significa que o tema abordado teve como foco questões políticas, sociais, econômicas e/ou culturais sobre a América Latina como um todo, não tendo como foco país ou países. A mesma explicação é válida quando nos referimos que a pesquisa teve como tema a História Latino-americana.
} 
Os trabalhos apresentados têm em sua maioria, origem de pesquisadores provenientes do Rio Grande do Sul, Rio de Janeiro, Goiás e Bahia. As temáticas trabalhadas e apresentadas são, principalmente, sobre a América Latina, sobre a Região Platina e comparativo entre Brasil e Argentina.

Já o V Encontro da ANPHLAC aconteceu entre os dias 24 e 26 de julho de 2002 na cidade de Belo Horizonte-MG. Segundo a professora Kátia Gerab Baggio,

\begin{abstract}
A realização do V Encontro foi de grande relevância para o fortalecimento da ANPHLAC, tanto em razão da qualidade dos trabalhos apresentados como da quantidade de pesquisadores e ouvintes participantes. A Comissão Organizadora recebeu as inscrições de 93 pesquisadores para apresentação de trabalhos (dos quais apenas 10 não puderam comparecer ao evento) e de 147 ouvintes. (Anais do V Encontro ANPHLAC. Apresentação, Kátia G. Baggio, 2002, p.1)
\end{abstract}

Ainda segundo a professora, o Encontro contou com a participação de professores e pesquisadores de vários estados do Brasil, além de pesquisadores da Universidade de Buenos Aires-UBA, Argentina. Destacou também a participação expressiva de mestrandos e doutorandos de diferentes instituições, "demonstrando o crescimento do número de pesquisas na área de História das Américas". (Anais do $\mathrm{V}$ Encontro ANPHLAC. Apresentação, Kátia G. Baggio, 2002)

O número de 147 ouvintes revela o aumento do interesse pela área de História das Américas. Isso pode ser confirmado segundo a professora Kátia Gerab Baggio, pela participação de "alunos de graduação e pós-graduação em História, estudantes de áreas afins e professores de ensino fundamental, médio e superior". (Anais do V Encontro ANPHLAC. Apresentação, Kátia G. Baggio, 2002)

Ao se observar os artigos publicados nos Anais, percebe-se que a produção em História das Américas foi predominante. Os professores e pesquisadores vieram, sobretudo, de São Paulo, Rio de Janeiro, Rio Grande do Sul e Minas Gerais. Os temas mais abordados foram sobre América Latina, México e Cuba. Todos os pesquisadores atuavam em universidades e instituições de pesquisa do Brasil. A grande maioria dos estudos foi de pesquisadores brasileiros sobre América Latina, México, Cuba, Colômbia e o Paraguai.

O VI Encontro realizado em Maringá no Paraná, entre os dias 20 e 23 de Julho de 2004, contou com a inscrição de 153 trabalhos e 302 inscritos como ouvintes. 
Segundo o professor Luiz Felipe Viel Moreira isto se deveu a três motivos: primeiro, "o evento se realizou durante o período letivo, tendo o Departamento de História suspendido as aulas para que viesse a ocorrer um maior envolvimento dos acadêmicos"; segundo, "foi a vinda do grupo expressivo de alunos paraguaios"; terceiro, "a participação de professores do ensino médio vindos da região de influência de Maringá”. (Anais do VI Encontro ANPHLAC. Apresentação Luis Felipe Viel Moreira, 2004)

Ainda segundo o professor,

A realização do VI Encontro foi importante para a ANPHLAC, pois pela primeira vez se realizou em uma universidade do interior, saindo do circuito das capitais como até então se realizou. Assim, havia toda uma responsabilidade e expectativa, e que ao final não foram frustradas. A qualidade dos trabalhos apresentados, como a quantidade de pesquisadores e ouvintes participantes excedeu ao esperado. Cabe mencionar que o evento, apesar de ser um encontro nacional, reuniu pesquisadores de diversos países latino-americanos (argentinos, paraguaios, e mexicanos), bem como espanhóis. Cabe uma menção especial a presença de toda uma delegação paraguaia, com 98 (noventa e oito) alunos da Universidad Nacional de Asunción, que vieram acompanhados de seus professores. Também numerosa foi a presença de pesquisadores argentinos, vindos das mais diversas regiões, desde a área missioneira e chaquenha, até o sul patagônico. (Anais do VI Encontro ANPHLAC. Apresentação Luis Felipe Viel Moreira, 2004)

Este Encontro foi o primeiro que aconteceu após a mudança no estatuto e a inclusão dos Estados Unidos e Canadá. A maioria dos participantes veio de São Paulo, Rio de Janeiro e Assunção no Paraguai. As temáticas mais abordadas foram sobre Argentina e Estados Unidos. A grande maioria dos estudos foi de pesquisadores brasileiros sobre temas latino-americanos, destacando-se os estudos sobre América Latina, Argentina e Estados Unidos. Nota-se, a partir deste encontro, uma inflexão para a História das Américas ${ }^{8}$ e um marco importante na trajetória da Associação, que foi a participação contundente de estudantes de fora do Brasil e de professores do Ensino Médio da região, demonstrando que os Encontros podem e devem acontecer também nas cidades do interior.

\footnotetext{
${ }^{8}$ No primeiro Encontro imediatamente após a Associação ter passado a se dedicar sobre aos estudos da História das Américas, já é possível notar o surgimento - ao menos no âmbito da ANPHLAC - dos primeiros estudos sobre Estados Unidos da América e Canadá.
} 
O VII Encontro foi realizado na Cidade de Campinas (PUC-Campinas), entre os dias 10 e 13 de outubro de 2006. Segundo o professor José Alves de Freitas Neto, secretário da ANPHLAC (2004-2006),

O Encontro teve a proposição de 64 mesas-redondas que aglutinaram 206 trabalhos inscritos, dos quais 42 não foram apresentados. A avaliação do Encontro foi bastante positiva refletindo o crescimento das pesquisas relacionadas à História das Américas e Caribe no Brasil e a oportunidade de integração entre pessoas oriundas das principais universidades brasileiras e dos países presentes ao Encontro. (Anais do VII Encontro ANPHLAC. Apresentação, José A. F. Neto, 2006)

Ainda segundo o professor "O número de ouvintes foi expressivo, tanto de estudantes da região de Campinas, oriundos da PUC e da UNICAMP (Universidade Estadual de Campinas), como os que vieram de outras localidades". O Encontro contou com duas Conferências, a de abertura realizada pelo professor doutor Hector Hernan Bruit (UNICAMP) intitulada "A construção de uma cultura criolla na América Latina"; e a Conferência de encerramento com a professora doutora Patrícia Funes (Universidad de Buenos Aires - UBA) intitulada "Censura, Cultura y Represión en Argentina a través de los Servicios de Inteligencia del Estado". (Anais do VII Encontro ANPHLAC. Apresentação, José A. F. Neto, 2006)

Dos trabalhos apresentados e disponibilizados para compor os Anais do Encontro, temos a maioria dos participantes oriundos São Paulo e Rio de Janeiro, em terceiro lugar trabalhos provenientes do Paraná e Santa Catarina. Tivemos também a participação de cinco pesquisadores da Argentina, um pesquisador do México e um pesquisador de Israel.

Neste Encontro, a maioria dos estudos foi de pesquisadores brasileiros ou que atuam no Brasil sobre a temática latino-americana como um todo, cerca de vinte trabalhos. Cerca de seis estudos sobre o Uruguai, seis sobre a Argentina, seis estudos sobre os Jesuítas na América Latina, três estudos comparativos Brasil-México, três sobre América do Sul, dois sobre o México e um estudo sobre Estados Unidos, Chile, Cuba, Paraguai e Bolívia.

O VIII Encontro Internacional da ANPHLAC aconteceu na cidade de Vitória-ES entre os dias 29 de Julho e 01 de Agosto de 2008 e, contou com a participação 
principalmente de pesquisadores provenientes das Universidades de São Paulo e Rio de Janeiro. Foram publicados 71 artigos nos anais do Encontro.

Segundo o professor Antonio Carlos Gil,

\begin{abstract}
A programação do VIII Encontro Internacional foi bastante diversificada. Destacamos, em primeiro lugar, nossos conferencistas. Abrindo as nossas atividades, o prof. Dr. Ricardo Salvatore, da Universidade Torcuato Di Tella - Buenos Aires, proferiu a conferência "Los historiadores norteamericanos y la cuestión colonial en lãs Américas, 1900-1950". O prof. Dr. Jaime de Almeida, da Universidade de Brasília proferiu a conferência "História, memória e esquecimento: Santa Librada no Bicentenário da Independência da Colômbia”. Fechando o nosso evento, a profa. Dra. Maria Lígia Prado proferiu a conferência de encerramento tendo por tema "O sagrado e o Moderno: configurações pictóricas da Cultura Mexicana (1890-1920). Como uma das fundadoras da ANPHLAC gostaríamos de ressaltar também o caráter de homenagem de que se revestiu esta escolha. Tivemos, ainda, 175 congressistas com trabalho inscrito, distribuídos em 54 mesas-redondas, com uma variedade de temas significativa, distribuídas nos horários da manhã e da tarde. Deste total, 42 congressistas não compareceram e seus trabalhos não foram apresentados. Foram oferecidos, também, 7 mini-cursos. (Anais do VIII Encontro ANPHLAC. Apresentação, Antonio Carlos Gil, 2008)
\end{abstract}

As temáticas principais versaram sobre México, América Latina, Argentina, América Platina e estudos comparativos entre América Latina e Estados Unidos. A maioria dos trabalhos foi de pesquisadores brasileiros sobre História das Américas, com destaque para América, Argentina e México. Ainda são perceptíveis os poucos estudos sobre os países Andinos e da América Central, com destaque para um estudo sobre a Bolívia, três sobre o Chile e um sobre a Guatemala. Entretanto, figuraram nos Anais do Encontro mais estudos que tinham como objeto a América Platina.

O professor Antonio Carlos Gil destaca ainda que, desde o surgimento da Associação em 1992, a pesquisa nos diversos campos da História das Américas tem crescido significativamente, "graças às iniciativas desenvolvidas, tornaram-se mais numerosos os Pesquisadores e multiplicaram-se os títulos de livros de História das Américas Produzidos, fato que pode ser constatado pelo número de livros que foram lançados durante o evento". (Anais do VIII Encontro ANPHLAC. Apresentação, Antonio Carlos Gil, 2008) 
O IX e último Encontro ${ }^{9}$ que registramos aqui aconteceu na Universidade Federal de Goiás em Goiânia-GO. Sob a presidência da professora Fabiana de Souza Fredrigo o encontro aconteceu entre os dias 26 e 29 de julho de 2010.

As publicações nos Anais foram poucas, o que contrasta com o caderno de resumos, onde figura um número significativo de apresentações. Das publicações que aparecem nos Anais, o maior número delas se dedicou ao estudo biográfico de personalidades da História das Américas. Há também um estudo sobre Cuba, outro sobre a Bolívia e dois estudos que comparam América Latina e Europa. O estudo sobre a Bolívia é uma pesquisa comparativa Brasil-Bolívia.

O Encontro foi marcado pela homenagem que a Associação fez, através de alguns ex-alunos, à professora Maria Ligia Coelho Prado, lembrando a sua trajetória como professora e pesquisadora na área da História da América Latina e os anos dedicados ao tema como professora da Universidade de São Paulo - USP.

Desse modo, os Encontros aqui relatados, nos possibilitam perceber o crescimento da ANPHLAC e das pesquisas na área ao longo desses 20 anos, bem como o crescimento do interesse de professores e pesquisadores pela área.

\begin{abstract}
Podemos considerar, hoje, que nosso Encontro Internacional é o maior evento de historiadores brasileiros que pesquisam na área de História das Américas, como demonstram a quantidade de inscritos e o número de mesas redondas. Provenientes de diversas regiões do país e também do exterior, os trabalhos inscritos nos apresentam os resultados de pesquisas e debatem variados temas diretamente relacionados à História das Américas. Uma rica e complexa rede de relações individuais e interinstitucionais se estabeleceu, favorecendo a riqueza e a variedade de intercâmbios intelectuais. (Anais do VIII Encontro ANPHLAC. Apresentação, Antonio Carlos Gil, 2008)
\end{abstract}

A outra fonte de publicação dos estudos realizados pelos pesquisadores de História das Américas é a Revista Eletrônica da ANPHLAC que, ao longo de seus 13 números, têm mostrado uma produção vigorosa e variada, evidenciando não só o crescimento da Associação - assim como os Anais - , como a sua tendência a partir de 2002/2004 para uma História das Américas, retratado, sobretudo, na edição de número 7, com a publicação do Dossiê Estados Unidos.

As publicações até o ano de 2012 chegam a um número de aproximadamente 88 artigos e uma dezena de resenhas. Inicialmente com temáticas voltadas para a América

\footnotetext{
${ }^{9}$ Há poucas informações sobre o Encontro nos Anais que constam do site da ANPHLAC. 
Latina, foram abordados, principalmente, temas como: o Ensino de História da América, a produção bibliográfica sobre História da América no Brasil e estudos comparativos entre Brasil e América do Sul e Região Platina.

Após o número 5, a Associação começou a produzir Dossiês temáticos, cujos temas versaram sobre: Representações e Imaginário Político nas Américas; História e Arte nas Américas; Estados Unidos; Memória e Comemorações: história e historiografia das Américas; Nas Américas, sobre as Américas: redes de conhecimento e circulação de ideias; Cultura e autoritarismo nas Américas; História e violência, discursos e identidades; Intelectuais, identidades e discursos na América Latina do século XX; Intelectuais, nações e identidades nas Américas - século XIX e início do século $X X$.

O primeiro número da Revista Eletrônica da ANPHLAC abordou a problemática da História Latino-americana, as discussões tiveram como foco a produção bibliográfica e a pesquisa em História da América Latina no Brasil, indo ao encontro da preocupação que motivou a criação da Associação em 1993, ou seja, fomentar os estudos, as pesquisas e as publicações de História da América Latina no país.

A partir do número dois, a Revista passou a publicar temas variados sobre a História Latino-americana e caribenha, possibilitando uma divulgação das produções e pesquisas que vinham sendo realizadas naquele momento no Brasil. É possível perceber já neste número uma tendência a se discutir determinados temas, até culminar, após o número quatro, com o início da publicação de Dossiês Temáticos, conforme podemos observar no quadro abaixo.

Quadro 3 - Dossiês temáticos publicados pela Revista Eletrônica ANPHLAC

\begin{tabular}{|c|c|c|c|c|c|c|c|c|c|c|}
\hline Dossiê $^{10} /$ origem & 1 & 2 & 3 & 4 & 5 & 6 & 7 & 8 & 9 & Total \\
\hline São Paulo & 1 & 2 & 2 & 1 & 5 & 2 & 4 & 4 & 2 & 22 \\
\hline Minas Gerais & 1 & & & & & & & & & 1 \\
\hline
\end{tabular}

${ }^{10}$ Dossiê: 1) Representações e Imaginário Político nas Américas; 2) História e Arte nas Américas; 3) Estados Unidos; 4) Memória e Comemorações: história e historiografia das Américas; 5) Nas Américas, sobre as Américas: redes de conhecimento e circulação de ideias; 6) Cultura e autoritarismo nas Américas; 7) História e violência, discursos e identidades; 8) Intelectuais, identidades e discursos na América Latina do século XX; e 9) Intelectuais, nações e identidades nas Américas - século XIX e início do século XX.

* Artigos publicados por dois ou mais autores. 


\begin{tabular}{|c|c|c|c|c|c|c|c|c|c|c|}
\hline $\begin{array}{c}\text { Rio de Janeiro } \\
\text { Rio Grande do } \\
\text { Sul }\end{array}$ & 1 & & 1 & & $1 *$ & & & & & $\mathbf{3}$ \\
\hline Piauí & & 1 & & & & & & & & $\mathbf{1}$ \\
\hline Israel & & 1 & & & & & & & & $\mathbf{1}$ \\
\hline Espírito Santo & & & & 1 & & & & 2 & & $\mathbf{3}$ \\
\hline Goiás & & & & $1 *$ & & & & & 1 & $\mathbf{2}$ \\
\hline México & & & & & 1 & & & & & $\mathbf{1}$ \\
\hline Paraná & & & & & 1 & & & & & $\mathbf{1}$ \\
\hline Brasília & & & & $1 *$ & & & & & & $\mathbf{1}$ \\
\hline Santa Catarina & & & & & $1 *$ & 1 & & 1 & & $\mathbf{3}$ \\
\hline Argentina & & & & & & 2 & 2 & 2 & $4 *$ & $\mathbf{1 0}$ \\
\hline Bahia & & & & & & & & & 1 & $\mathbf{1}$ \\
\hline Total & $\mathbf{4}$ & $\mathbf{5}$ & $\mathbf{5}$ & $\mathbf{3}$ & $\mathbf{1 0}$ & $\mathbf{5}$ & $\mathbf{6}$ & $\mathbf{1 1}$ & $\mathbf{1 0}$ & $\mathbf{5 9 / 6 2 *}$ \\
\hline
\end{tabular}

Fonte: Revista Eletrônica da ANPHLAC. www.anphlac.org.

Os dados aqui apontados demonstram de maneira contundente o processo de crescimento da ANPHLAC durante os 20 anos de sua existência. Apontam para um crescimento na produção e o aumento na participação dos professores, pesquisadores e estudantes da área de História das Américas. Entretanto, alguns dados nos chamam a atenção e se mostram preocupantes, entre eles, a pouca participação nos Encontros de estudiosos da área das regiões Nordeste (a exceção do Encontro de Salvador-BA) e Norte, e na região Centro-oeste, com uma participação expressiva de Goiás, ficando à margem Mato Grosso, Mato Grosso do Sul e o Distrito Federal (a exceção do Encontro realizado em Brasília).

Porém, a trajetória da História das Américas no Brasil vem se consolidando ao longo dos últimos anos. Desde sua fundação, a produção intelectual dentro e fora da ANPHLAC tem sido variada e ampla, destacando-se, sobretudo uma produção voltada para estudos comparativos, estudos sobre Brasil, México, Argentina e Estados Unidos, como demonstram os trabalhos publicados nos anais dos Encontros, os artigos e Dossiês publicados na Revista Eletrônica da ANPHLAC. 
"A publicação de textos produzidos por pesquisadores que investigam temáticas de História Latino-americana" e História das Américas no Brasil "constitui uma das formas mais contundentes de demonstração de que esta tarefa é viável e pertinente, testemunhando ainda a vitalidade da ANPHLAC". (Reichel e Gebran, in Jaime Almeida, 1998, p. 6, com modificações)

Outras razões serão explicitadas nas considerações finais, mas já é possível perceber que a geografia do Brasil traz algumas limitações, como o deslocamento para participar dos Encontros, além de, possivelmente, a quase inexistência de financiamento para que os pesquisadores possam participar dos Encontros Bianuais.

\section{Considerações Finais: a ANPHLAC hoje}

Ao observarmos a produção de artigos nos Anais dos Encontros da ANPHLAC, podemos perceber que a produção em História das Américas encontra-se localizada, sobretudo, no eixo sudeste-sul, de onde se origina a maioria das publicações, sobretudo São Paulo, Rio de Janeiro, Rio Grade do Sul e Goiás.

Neste sentido, a produção regional de História das Américas, quando levado em consideração os Encontros realizados, ainda está concentrada em duas regiões brasileiras, com o predomínio da região Sudeste. Isto talvez possa ser explicado pelo local onde os Encontros têm acontecido. Foram dois Encontros no Centro-Oeste, um no Nordeste, um no Sul e seis no Sudeste. Quando levamos em consideração a Revista Eletrônica da ANPHLAC, esta produção está um pouco mais dispersa, tendo uma participação significativa de estrangeiros com destaque para os pesquisadores da Argentina.

Contudo, o levantamento feito das produções da ANPHLAC ao longo deste artigo - que estão longe de ser exaustivos -, demonstram a vitalidade da Associação durante duas décadas de existência. Os artigos e trabalhos publicados em anais e na Revista estão na casa de centenas.

Os temas mais abordados são estudos comparativos entre Brasil e países latinoamericanos, com o predomínio de estudos sobre o México e Argentina, além do aumento significativo dos estudos sobre Estados Unidos após o ano de 2004 no Encontro realizado em Maringá-PR, o primeiro fora das Capitais. 
Evidentemente que as razões são muito complexas, mas é possível considerar os dados como fatores importantes que determinam essas produções e a necessidade ainda, de que a área possa se expandir para a fronteira oeste do Brasil, principalmente se levarmos em consideração que o nosso país faz fronteiras com quase todos os países da América do Sul.

Dados recentes apontam que há novos estudos sendo realizados pelas Universidades que surgiram na fronteira oeste do Brasil nos primeiros anos do século XXI e, que, discutem as questões fronteiriças e da História das Américas, é o caso, por exemplo, de pesquisas que vêm sendo realizadas por Cientistas Sociais e Historiadores da Universidade Federal de Mato Grosso do Sul (UFMS), Universidade Federal da Grande Dourados (UFGD), Universidade do Estado de Mato Grosso (UNEMAT) e Universidade Federal da Integração Latino-americana (UNILA).

Neste sentido, quando falamos na dimensão nacional da ANPHLAC e a pesquisa nas diversas regiões brasileiras, podemos analisá-la por duas vias, a primeira é a sua consolidação, fato incontestável como demonstram os dados da produção, por outro lado, ainda é preciso uma política efetiva de aproximação com as regiões mais distantes do Brasil, o que implicaria em trazer para a Associação novos pesquisadores e os estudos supracitados que estão sendo desenvolvidos nas Universidades recém-criadas.

Entretanto, segundo a professora Philomena Gebran, "vale acrescentar que desde a sua criação, a ANPHLAC vem crescendo em conceito e reconhecimento da comunidade acadêmica e, aumentando sensivelmente o número de sócios, o que é uma grande satisfação para nós que lutamos pela sua criação durante anos". (Gebran, Revista Eletrônica da ANPHLAC, No. 1, 2001, p. 6)

Finalmente e diante do exposto, seria interessante que a ANPHLAC pudesse publicar mais livros, como os que foram organizados pelas professoras Philomena Gebran e Maria Teresa T. B. de Lemos e pelo professor Jaime de Almeida, bem como a realização de Encontros itinerantes nas regiões brasileiras - ou a realização de Simpósios Temáticos nessas regiões, com o apoio da Associação e que fosse um preâmbulo dos Encontros Nacionais, podendo os mesmos acontecer em anos ímpares -, mesmo nas mais distantes e que a Diretoria pudesse ser composta - em seus cargos por pesquisadores das mais diversas regiões, possibilitando uma divulgação maior da Associação, seus estudos e pesquisadores. 


\section{Referências e Fontes}

ALMEIDA, Jaime de (org). Caminhos da História da América no Brasil: tendências e contornos de um campo historiográfico. ANPHLAC, Brasília, 1998.

ANPHLAC. Anais dos Encontros. In: www.anphlac.org. Acesso em 15/11/2012.

ANPHLAC. Revista Eletrônica da ANPHLAC. In: www.anphlac.org. Acesso em $15 / 11 / 2012$.

ANPHLAC. Site da Associação. In: www.anphlac.org. Acesso em 15/11/2012.

GEBRAN, Philomena \& LEMOS, Maria Teresa T. B. América Latina: Cultura, Estado e Sociedade. ANPHLAC, Rio de Janeiro, 1994.

UNESCO. Historia General de América Latina - los proyectos nacionales latinoamericanos: sus instrumentos y articulación, 1870-1930. Volume VII. Ed. Trotta, París, Francia, 2008. 